\section{Transfer effects of simple and detailed instructions in the presence and absence of pretraining in reversal and nonreversal shifts}

\author{
PAUL G. NEUMANN* \\ University of Texas at Austin, Austin, Tex. $78712 \dagger$
}

Two studies investigating the effects of pretraining and task instructions on transfer performance in reversal, nonreversal, and control shift paradigms were performed. In Experiment 1, all $S$ s received two unidimensional training problems, while task instructions and transfer paradigm were varied. In Experiment 2, task instructions, pretraining, and transfer paradigm were varied. Simple task instructions and the absence of pretraining both tend to facilitate reversal shifts and retard nonreversal shifts. Detailed task instructions and pretraining tend to facilitate nonreversal shifts and retard reversal shifts. It is suggested that a mechanism involving the presence or absence of a dimensional lose-shift strategy will account for the results.

Wolff (1967) states that, almost without exception, transfer performance on reversal shifts is superior to transfer performance on nonreversal shifts for adult Ss over a wide range of variables. Contrary to these well-established findings, Johnson (1966) found no difference in transfer performance between these two types of shifts. Subsequent research (Johnson, Fishkin, \& Bourne, $1966 \mathrm{a}, \mathrm{b})$ showed that the elimination of the difference in transfer performance was due to the use of detailed task instructions in the Johnson (1966) study. Specifically, Johnson et al (1966b) suggest that the critical factors in differentiating simple and detailed task instructions are labeling each dimension, indicating to $S$ that the solution is unidimensional, and demonstrating a possible solution to the problem as part of the task instructions.

Erickson (1971) reported a series of experiments in which interaction was

*This research was supported by a grant-in-aid made by the Psychology Department of the University of Texas at Austin and funded by the National Science Foundation Undergraduate Research Participation Program. In addition. computer time was made available at no cost to the author by the Computation Center of that university. Experiment 1 served as an honors thesis in partial fulfilment of the requirements for special honors in psychology. The data in Experiment 1 were reported at the 18 th Annual Convention of the Southwestern Psychological Association. The author wishes to thank Oren Dreeben for considerable aid in collecting the data reported in Experiment 2. Preparation of this paper was made possible by Research Grant MH 14314, awarded to Lyle E. Bourne, Jr., to whom the author expresses his sincere appreciation. This is Publication No. 24 of the Institute for the Study of Intellectual Behavior

How at the Institute for the Study of Intellectual Behavior, University of Colorado, Boulder, Colo. 80302. obtained between type of task instruction and shift type. Transfer performance of $\mathrm{Ss}$ who received detailed instructions was superior or equal in the nonreversal condition, whereas transfer performance of minimally instructed Ss was clearly superior in the reversal condition. Erickson attributes this to the care with which $E$ ensures that $\mathbf{S s}$ understand the instructions, When Ss understand the detailed instructions, they solve with a hypothesis-testing strategy, incorporating a dimensional lose-shift mechanism. On any trial following an error trial, $S$ formulates and tests a hypothesis based on a dimension other than the one upon which the hypothesis was based in the preceding exror trial, as opposed to a different hypothesis based upon the same dimension.

The finding that detailed task instructions eliminate the difference or reverse the order of difficulty of reversal and nonreversal shifts obtained with simple task instructions therefore appears to be replicable. It would not seem unreasonable to assume that the effect of detailed task instructions is that of conveying information about the nature of the problem and the possible solutions, inducing the formulation of solution strategies other than those used by Ss who lack this information. If this assumption is correct, then pretraining on similar problems should convey much the same information. The following experiments were designed to determine whether, in fact, that result obtains.

\section{EXPERIMENT 1 Design}

The basic design is a 2 by 3 factorial. All Ss solved a two-dimension training problem, a three-dimension training problem, and a five-dimension transfer task composed of an original learning problem and a transfer problem. All solutions were unidimensional, and all dimensions were bivalued. One-half of the Ss received simple task instructions, and the other half received detailed task instructions. The transfer task was either a reversal, a nonreversal, or a control shift. Requirements of the various shift paradigms were met in such a manner that all Ss solved an identical transfer problem.

\section{Subjects}

Ss were 72 undergraduate psychology students who volunteered for the experiment in partial fulfillment of optional course requirements. Their assignment across the six experimental conditions was based upon the order in which their names appeared on sign-up sheets.

\section{Materials}

Verbal stimuli were based on the superordinate categories listed under the heading "Dimension" in Table 1. Each list contained one value from each dimension printed in a vertical order. For each problem, all possible combinations of values and vertical orders were generated. FORTRAN IV programs were utilized to accomplish the generation of the random orders of presentation of the stimuli. (Listings of these programs are available on request to the author.) The first training problem incorporated 2 bivalued dimensions, which yields 8 presentations $\left(2^{2} \times 2 !\right)$. Each presentation was replicated 12 times for a total of 96 presentations. The second training problem incorporated 3 bivalued dimensions, which yields 48 presentations $\left(2^{3} \times 3\right.$ !), each of which was replicated twice for a total of 96 presentations. The original learning and transfer problems incorporated 5 bivalued dimensions, which yields a total of 3,840 presentations ( $2^{5} \times 5$ !), of which 96 were selected for each problem. Each list was printed in vertical order on a standard $4 \times 6$ notecard.

Two sets of instructions were utilized. Instructions for the simple instruction condition informed Ss that they would see a series of cards, each of which was capable of being classified into one of the two categories (labeled " $A$ " and "B"), and that their task was to discover how to determine the correct classification for each card. Instructions for the detailed instruction condition included explicit labeling of each dimension, listing all the possible unidimensional solutions, and the assurance that the correct solution was one of the unidimensional solutions listed. A separate set of instructions was given Ss prior to each problem, with the exception of the transfer problem. 
Table 1

\begin{tabular}{|c|c|c|c|}
\hline Problem & Dimension & & \\
\hline Training (1) & $\begin{array}{l}\text { Animals* } \\
\text { Colors }\end{array}$ & $\begin{array}{l}\text { Cat } \\
\text { Black }\end{array}$ & $\begin{array}{l}\text { Dog } \\
\text { White }\end{array}$ \\
\hline Training (2) & $\begin{array}{l}\text { Sizes* } \\
\text { Colors } \\
\text { Shapes }\end{array}$ & $\begin{array}{l}\text { Large } \\
\text { Red } \\
\text { Diamond }\end{array}$ & $\begin{array}{l}\text { Small } \\
\text { Green } \\
\text { Square }\end{array}$ \\
\hline $\begin{array}{l}\text { Original Learning } \\
\text { (Reversal and } \\
\text { Nonreversal) }\end{array}$ & $\begin{array}{l}\text { Vehicles* R } \\
\text { Clothing* NR } \\
\text { Tools } \\
\text { Furniture } \\
\text { Fruit }\end{array}$ & $\begin{array}{l}\text { Car } \\
\text { Shoe } \\
\text { Saw } \\
\text { Bed } \\
\text { Pear }\end{array}$ & $\begin{array}{l}\text { Boat } \\
\text { Hat } \\
\text { Wrench } \\
\text { Table } \\
\text { Cherry }\end{array}$ \\
\hline (Control) & $\begin{array}{l}\text { Flowers* } \\
\text { Metals } \\
\text { Trees } \\
\text { Insects } \\
\text { Birds }\end{array}$ & $\begin{array}{l}\text { Daisy } \\
\text { Tin } \\
\text { Oak } \\
\text { Hornet } \\
\text { Eagle }\end{array}$ & $\begin{array}{l}\text { Tulip } \\
\text { Aluminum } \\
\text { Elm } \\
\text { Wasp } \\
\text { Hawk }\end{array}$ \\
\hline Transfer Learning & $\begin{array}{l}\text { Vehicles* } \\
\text { Clothing } \\
\text { Tools } \\
\text { Furniture } \\
\text { Fruit }\end{array}$ & $\begin{array}{l}\text { Car } \\
\text { Shoe } \\
\text { Saw } \\
\text { Bed } \\
\text { Pear }\end{array}$ & $\begin{array}{l}\text { Boat } \\
\text { Hat } \\
\text { Wrench } \\
\text { Table } \\
\text { Cherry }\end{array}$ \\
\hline
\end{tabular}

*Denotes relevant dimension

A different set of random presentation sequences was utilized for each of the 10 basic replications of the six conditions. Response assignments were counterbalanced within conditions.

A blind with a lighted window was constructed in such a manner that when a card did not occupy the window, Ss were able to see only a white background.

$$
\text { Procedure }
$$

Upon entering the laboratory, Ss were handed the appropriate set of typewritten instructions. In the detailed instruction conditions, E ensured that Ss understood the instructions before beginning each problem, reinstructing from the typewritten instructions when necessary. When both $E$ and $S$ were satisfied that the instructions were understood, the experiment was begun. Cards were placed in the window, one at a time, in a predetermined random order. No limit on study time was imposed. Cards remained visible to $S s$ approximately $5 \mathrm{sec}$ after Ss answered, and there was a 5-sec intertrial interval. After each answer, $\mathrm{E}$ informed $\mathrm{Ss}$ as to whether that answer was correct, and what the correct answer for that card was. A learning criterion of 10 consecutive correct responses was used for all problems. Upon reaching criterion in the original learning problem, Ss were shifted without interruption to the transfer problem. After reaching criterion in the transfer problem, Ss were asked, "How do you know what is an 'A' and what is a " $B$ '?" to ensure that $S s$ knew the rule. Sixty Ss reached criterion. Twelve Ss were terminated as nonlearners on the first error following the 95th trial of a training problem or the original learning problem. In this manner, 4 Ss were terminated on the first training problem, 2 Ss on the second training problem, and 6 Ss on the original learning problem. Of Ss terminated on the original learning problem, 2 were from the detailed instruction group and 4 were from the simple instruction group.
Results

Since trials to last error and total errors to criterion yield nearly identical results, only total errors to criterion will be presented. No significant differences in performance between task instruction conditions were observed in the first training problem, $F(1,54)=1.03, p<.32$, the second training problem, $F(1,54)=$ $1.69, p<.20$, or the original learning problem, $\mathrm{F}(1,54)=.04, \mathrm{p}<.84$. Although the group means suggest a slight facilitative effect for the detailed instruction conditions, differences reduced across problems, and performance was nearly identical for the simple instruction group $(\overline{\mathrm{X}}=$ $6.73, \mathrm{SD}=6.73$ ) and the detailed instruction group $(\overline{\mathrm{X}}=6.37, \mathrm{SD}=$ 7.48 ) on the original learning problem.

On the transfer problem, no significant differences were obtained for instruction condition, $F(1,54)=$ $.04, \mathrm{p}<.83$, or transfer paradigm, $\mathrm{F}(2,54)=1.43, \mathrm{p}<.25$. However, significant interaction was observed, $F(2,54)=4.95, p<.01$.

Figure 1 illustrates the interaction between instruction condition and

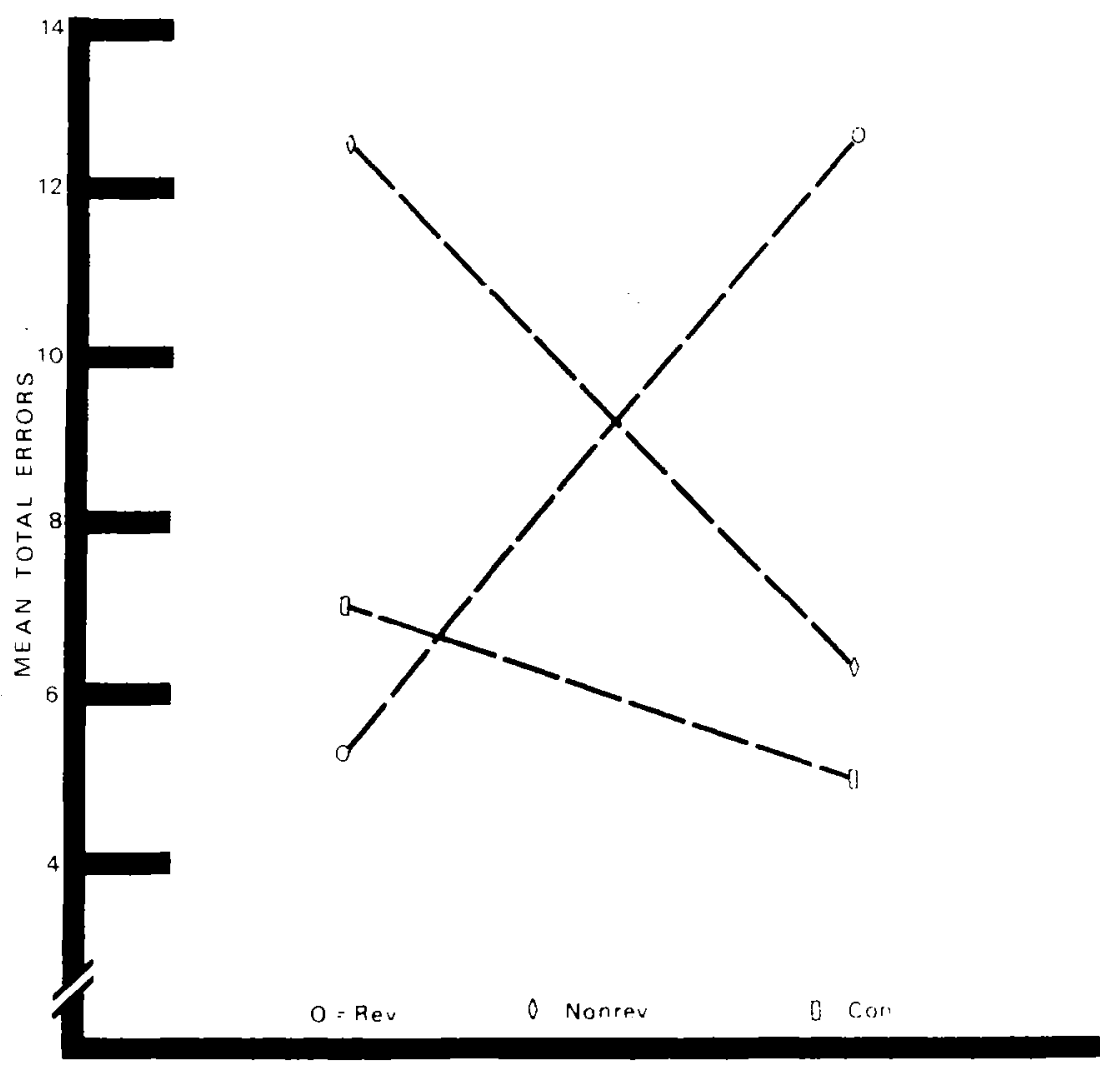

Simple

INSTRUCTIONS

Fig. 1. Mean total errors to criterion in transfer problems, Experiment 1. 
Table 2

Mean Original Learning Errors

Experiment 2

\begin{tabular}{|c|c|c|c|c|}
\hline & \multicolumn{2}{|c|}{$\begin{array}{c}\text { Simple } \\
\text { Instructions }\end{array}$} & \multicolumn{2}{|c|}{$\begin{array}{c}\text { Detailed } \\
\text { Instructions }\end{array}$} \\
\hline & Mean & $\mathrm{SD}$ & Mean & $\mathrm{SD}$ \\
\hline $\begin{array}{l}\text { No } \\
\text { Training }\end{array}$ & 15.41 & 10.42 & 5.50 & 2.50 \\
\hline $\begin{array}{c}\text { Two } \\
\text { Problems }\end{array}$ & 6.31 & 1.13 & 3.54 & 1.54 \\
\hline
\end{tabular}

transfer paradigm. For the simple instruction condition, the reversal shift $(\overline{\mathrm{X}}=5.30, \mathrm{SD}=6.00)$ is easier than the nonreversal shift $(\bar{X}=12.70, S D=$ $10.75)$. For the detailed instruction condition, the nonreversal shift $(\overline{\mathrm{X}}=$ $6.30, \mathrm{SD}=4.30$ ) is easier than the reversal shift $(\overline{\mathrm{X}}=12.60, \mathrm{SD}=6.75)$.

As Experiment 1 progressed, there emerged an apparent regularity in the manner in which Ss reported the rule that they had utilized for assigning presentations to the two response categories. Specifically, Ss in the detailed instruction conditions reported a binary rule (e.g., "Car is 'A,' and boat is 'B."'), whereas Ss in the simple instruction conditions tended to report the rule in terms of the presence or absence of a single stimulus item (e.g., "If car is there, it's 'A,' and if car isn't there, it's 'B." ). Since $E$ discovered this apparent regularity after several $S s$ had completed the experiment, no accurate account was kept of these data. This discovery, however, in addition to the fact that pretraining was held constant in Experiment 1, justified a second experiment in which the effects of both pretraining and task instruction on both transfer performance and the type of rule reported could be observed. Experiment 2 was designed to meet these criteria.

\section{EXPERIMENT 2}

\section{Design}

The basic design was identical to Experiment 1, with the exception that the variable of pretraining vs no pretraining was added, resulting in a 2 by 2 by 3 factorial design.

\section{Subjects}

Ss were 111 undergraduate psychology students obtained and assigned in the manner described for Experiment 1.

\section{Materials}

Verbal stimuli were those utilized in Experiment 1, with the exception that the word "bus" was substituted for "boat" to eliminate the possibility that the reporting of a presence-absence rule in the simple instruction condition was an artifact of the obscurity of the superordinate category "vehicles," and the word " $z$ inc", was substituted for "aluminum" to make word length more uniform (see Table 1). The stimuli were printed horizontally on standard data processing cards, which permitted rapid and accurate duplication of the card decks.

\section{Procedure}

Procedure was identical to that of Experiment 1. Ninety-six Ss reached a criterion of 10 consecutive correct responses on the transfer problem. Fifteen Ss were terminated on the first error following the $95 \mathrm{th}$ trial of a training problem or the original learning problem. In this manner, $1 \mathrm{~S}$ was terminated on the first training problem and $3 \mathrm{Ss}$ were terminated on the second training problem. Of the 11 Ss terminated on the original learning problem, 5 Ss were in the simple instruction/no-training condition, 3 Ss were in the simple instruction/pretraining condition, and $1 \mathrm{~S}$ was in the detailed instruction/pretraining condition.

Analyses of variance were performed for all problems. No significant differences in performance between task instruction conditions were observed in the first training problem, $F(1,46)=.02, p<.87$, or the second training problem, $F(1,46)<1, p<.94$. In the original learning problem, significant differences were observed for task instruction, $\mathrm{F}(1,84)=15.65$, $\mathrm{p}<.0004$, training condition, $\mathrm{F}(1,84)$ $=12.67, \mathrm{p}<.0009$, and the interaction, $F(1,84)=5.39, \mathrm{p}<.02$. An examination of Table 2 indicates that the results are primarily due to the fact that, in general, performance was better with pretraining than without it, but that the detailed instructions not only facilitated performance in general but had a disproportionate effect in the no-training condition, thus significantly reducing the difference between the two pretraining conditions. To determine if this relationship generalized to the transfer problem, a product-moment correlation was performed between original learning and transfer errors. The results indicate that there was essentially no correlation $(x=-.01)$.

In the transfer problem, no significant differences were observed for task instructions, $F(1,84)=.04$, $\mathrm{p}<.84$, training condition, $\mathrm{F}(1,84)=$ $1.93, \mathrm{p}<.17$, or transfer paradigm, $F(2,84)=1.07, p<.35$. However, all two-way interactions were significant. Significant interaction was obtained between task instructions and training condition, $F(1,84)=4.47, p<.04$. An examination of Table 3 indicates that, whereas in the original learning problem detailed instructions reduced the difference in performance between pretraining conditions, in the transfer problem, the opposite result obtains. A comparison of cell means within the detailed instruction condition shows clearly that the primary source of this difference lies in the reversal shift condition. The addition of pretraining significantly retards performance on the reversal shift in the detailed instruction condition. The significant interaction between task instructions and transfer paradigm, $F(2,84)=9.93$, $\mathrm{p}<.0003$, essentially replicates the results of Experiment 1. With simple instructions, the reversal shift is superior to the nonreversal shift, whereas with detailed instructions, the nonreversal shift is superior to the reversal shift.

Table 3 indicates that the significant interaction between pretraining condition and transfer paradigm, $\mathrm{F}(2,84)=3.48, \mathrm{p}<.03$, is due to the fact that the addition of pretraining retards performance on reversal shifts and facilitates performance on nonreversal shifts, with the greatest effect being on the reversal shift. The three-way interaction between instruction condition, pretraining condition, and transfer paradigm was not statistically significant, $F(2,84)=$ $1.58, \mathrm{p}<.21$.

Results of the type of rule reported are as listed in Table 4. Significant differences in the type of rule reported were obtained, $\chi^{2}(3)=25.995$, $\mathrm{p}<.001$.

\section{DISCUSSION}

The results clearly indicate that the addition of pretraining problems and the addition of detailed task instructions result in similar effects upon performance on reversal and nonreversal shifts but that the number of pretraining problems incorporated here is not alone sufficient to induce a solution strategy that results in transfer performance for nonreversal shifts superior to reversal shifts. This basic result is corroborated by the distribution of the data in Table 4, which indicate that the major split in the type of rule reported is between task instruction conditions. Ss who received simple task instructions reported a rule based upon the presence or absence of a single value of the relevant dimension, indicating that the binary nature of the dimensions was not apparent and that labels had not been assigned to the dimensions. For example, they were not aware that the value "pear" and the value "cherry" constituted a single binary dimension, the label of which was "fruit." Nor were these Ss aware that only one of these values appeared in any given presentation. Table 4 indicates that these data are only slightly affected by the pretraining variable. In the presence of detailed 
Table 3

Mean Transfer Errors: Experiment 2

\begin{tabular}{|c|c|c|c|c|c|}
\hline & & \multicolumn{2}{|c|}{ Simple Instructions } & \multicolumn{2}{|c|}{ Detailed Instructions } \\
\hline & & Mean & SD & Mean & $\mathrm{SD}$ \\
\hline $\begin{array}{l}\text { No } \\
\text { Training }\end{array}$ & $\begin{array}{l}\text { Reversal } \\
\text { Nonreversal } \\
\text { Control }\end{array}$ & $\begin{array}{r}3.88 \\
14.75 \\
4.13\end{array}$ & $\begin{array}{l}2.23 \\
9.82 \\
3.60\end{array}$ & $\begin{array}{l}5.25 \\
3.50 \\
4.88\end{array}$ & $\begin{array}{l}3.01 \\
2.39 \\
3.64\end{array}$ \\
\hline $\begin{array}{l}\text { Two } \\
\text { Problems }\end{array}$ & $\begin{array}{l}\text { Reversal } \\
\text { Nonreversal } \\
\text { Control }\end{array}$ & $\begin{array}{l}4.50 \\
8.62 \\
6.75\end{array}$ & $\begin{array}{l}4.50 \\
3.85 \\
5.52\end{array}$ & $\begin{array}{r}16.38 \\
4.38 \\
6.75\end{array}$ & $\begin{array}{r}15.00 \\
4.00 \\
5.34\end{array}$ \\
\hline \multicolumn{2}{|c|}{$\begin{array}{l}\text { Instructions by } \\
\text { Transfer Task }\end{array}$} & Mean & \multicolumn{2}{|c|}{$\begin{array}{l}\text { Training by } \\
\text { Transfer Task }\end{array}$} & Mean \\
\hline Simple & $\begin{array}{l}\text { Reversal } \\
\text { Nonreversal } \\
\text { Control }\end{array}$ & $\begin{array}{r}4.19 \\
11.69 \\
5.44\end{array}$ & $\begin{array}{l}\text { No } \\
\text { Training }\end{array}$ & $\begin{array}{l}\text { Reversal } \\
\text { Nonreversal } \\
\text { Control }\end{array}$ & $\begin{array}{l}4.56 \\
9.13 \\
4.50\end{array}$ \\
\hline Detailed & $\begin{array}{l}\text { Reversal } \\
\text { Nonreversal } \\
\text { Control }\end{array}$ & $\begin{array}{r}10.81 \\
3.94 \\
5.81 \\
\end{array}$ & $\begin{array}{l}\text { Two } \\
\text { Problems }\end{array}$ & $\begin{array}{l}\text { Reversal } \\
\text { Nonreversal } \\
\text { Control }\end{array}$ & $\begin{array}{r}10.44 \\
6.50 \\
6.75\end{array}$ \\
\hline & & \multicolumn{2}{|c|}{$\begin{array}{l}\text { Instructions by Training } \\
\text { Mean }\end{array}$} & & Mean \\
\hline Simple & $\begin{array}{l}\text { No Training } \\
\text { Two Problems }\end{array}$ & $\begin{array}{l}7.58 \\
6.63\end{array}$ & Detailed & $\begin{array}{l}\text { No Training } \\
\text { Two Problems }\end{array}$ & $\begin{array}{l}4.54 \\
9.17\end{array}$ \\
\hline
\end{tabular}

instructions, the pretraining variable shows no effect on these data. Inspection of Table 3 reveals unambiguously that the basic interaction between task instructions and transfer paradigm is not dependent upon the presence of pretraining, as Erickson (1971), Experiment V, would also indicate. The possibility that these results are an artifact of the type of stimulus materials used may be dismissed. The present studies incorporated veribal stimuli, whereas Erickson (1971), Experiment $\mathrm{V}$, incorporated geometric stimuli. The results are compatible.

Whether the interaction between instructions and transfer paradigm is dependent upon all instruction components as listed in Johnson et al $(1966 \mathrm{~b})$ is not clear. The present data suggest that the critical factor in obtaining results of performance on nonreversal shifts superior to reversal shifts may be whether Ss are aware of the organization of items into dimensions of more than one value and that the basic strategy for obtaining the solution, as reflected in Ss' reports of the rule utilized for assigning presentations to a response category, may differ fundamentally between Ss who are aware and Ss who are unaware of this organization.

There is at least one mechanism which would account for the results on this basis. Since Ss in the detailed instruction condition are aware of the binary nature of the dimensions, the probability is greater that they would discover that positive feedback can be obtained for several consecutive trials when the dimension being tested covaries with the relevant dimension and that an error trial following a series of correct trials is an indication that the wrong dimension is being tested. For example, if " $A$ " is the relevant dimension and " $\mathrm{C}$ " is the dimension being tested, as long as " $\mathrm{A}_{1}$ " consistently appears with " $\mathrm{C}_{1}$ " and " $\mathrm{A}_{2}$ " consistently appears with " $\mathrm{C}_{2}$," $\mathrm{S}$ can consistently state the correct responses without having discovered the relevant dimension. However, as soon as " $A_{1}$ " appears with " $\mathrm{C}_{2}$ " or " $\mathrm{A}_{2}$ " appears with " $\mathrm{C}_{1}, " \mathrm{~S}^{2}$ will state the incorrect response and feedback will indicate that the wrong dimension was being tested. Since the shift occurs after a criterion of several consecutive correct responses has been reached, the situation resembles that described above. Thus, Ss who are aware of the ramifications of chance covariance between dimensions drop the dimension which is relevant in the original learning problem and attempt to find the dimension which they presume had covaried with this dimension.

The plausibility of this mechanism is supported by the conclusion of Erickson (1971) that thoroughly instructed Ss tend to resample from a dimension other than the one upon which the immediately previous hypothesis was based. This mechanism would also account for the lesser but nevertheless significant interaction between training condition and transfer paradigm observed in Experiment 2, since a certain number of Ss would be expected to discover the binary nature of the dimensions as a function of pretraining. It would further account for the fact that the pretraining variable shows a slight effect upon the type of rule reported in the presence of simple task instructions but not in the presence of detailed task instructions, since the dimensional nature of the problem is made apparent by the detailed task instructions.

This mechanism is not to be confused with the dimensional mediating mechanisms posited by Kendler \& Kendler (1962). In mediational S-R theory, the dimensional mediator is acquired as a function of the strength of the association between the stimulus and the relevant dimension, and the strength of the association between the relevant dimension and the sorting responses. The superiority of the reversal shift over the nonreversal shift is accounted for by the fact that, in a reversal shift, only the incorrect sorting responses must be unlearned and the correct sorting responses learned, whereas, in a nonreversal shift, both the mediational response and the sorting responses must be unlearned and the correct mediational response and sorting responses learned.

The present mechanism posits selective attention as a function of the hypothesis testing strategy. The exact nature of the hypotheses, and therefore the focus of attention, is determined by whether or not the dimensional nature of the problem is apparent to Ss. It postulates that in the presence of simple instructions, the dimensional nature of the problem is not apparent, and hypotheses are based on the presence or absence of a single value. Attention is therefore focused on a single value, and the superiority of the reversal shift is due to the tendency of Ss to incorporate the previously relevant value in hypotheses selected or constructed following the shift. On the surface, this behavior cannot be differentiated from that predicted by the mediational S-R model. Ss' reports of the type of rule utilized (Table 4) indicate, however, that attention is focused on a value rather than on a dimension, as the S-R model specifies.

In the presence of detailed task instructions, the dimensional nature of the problem is apparent and the hypotheses are based on the binary values of a dimension. Attention is therefore focused on a dimension. However, when the ramifications of

Table 4

Type of Rule Reported: Experiment 2

\begin{tabular}{lccccc}
\hline & $\begin{array}{c}\text { Simple } \\
\text { Instructions }\end{array}$ & & \multicolumn{1}{c}{$\begin{array}{c}\text { Detailed } \\
\text { Instructions }\end{array}$} \\
\cline { 2 - 3 } $\begin{array}{c}\text { Rule } \\
\text { Reported }\end{array}$ & $\begin{array}{c}\text { No } \\
\text { Train- } \\
\text { ing }\end{array}$ & $\begin{array}{c}\text { Two } \\
\text { Prob- } \\
\text { lems }\end{array}$ & & $\begin{array}{c}\text { No } \\
\text { Train- } \\
\text { ing }\end{array}$ & $\begin{array}{c}\text { Two } \\
\text { lems }\end{array}$ \\
\hline $\begin{array}{l}\text { Binary } \\
\begin{array}{l}\text { Single } \\
\text { Value }\end{array}\end{array}$ & 8 & 10 & & 21 & 21 \\
\hline
\end{tabular}


chance covariance between dimensions are understood, there is a specific tendency not to test the same dimension following an error trial. Attention is shifted to another dimension by the process of selecting or constructing a locally consistent hypothesis (Gregg \& Simon, 1967) based upon a different dimension. Thus, in neither case is any unlearning postulated. Shifts in attention are an instantaneous function of the selection or construction of a new hypothesis rather than of a temporal process of unlearning old associations and learning new ones.

The finding that under simple instruction conditions, the rule utilized for solution is based upon a single value is not critical in accounting for the present results. The critical factor is whether or not Ss understand the nature of chance covariance between dimensions, thus defeating dimensional perseverance following a shift. It is not apparent how mediational $S-R$ theory might account for the instantaneous unlearning of the dimensional mediator, which is critical in accounting for performance under conditions of detailed task instructions.

\section{REFERENCES}

ERICKSON, J. R. Problem shifts and hypothesis behavior in concept identification. American Journal of Psychology, 1971, 84, 100-111.

GREGG, L. W., \& SIMION, H. A. Process models and stochastic theories of simple concept formation. Journal of Mathematical Psychologs, 1967, 4.

$246-276$.
JOHNSON, P. J. Factors affecting transfer in concept identification problems. Journal of Experimental Psychology. 1966.72, 655-660.

JOHNSON P J, FISHKIN A. \& BOURNE, L. F., JIR. Effects of BOURNE, L. E., JR. Effects of
procedural variables upon reversal and interdimensional shift performance: I Psychonomic Science, 1966a, 4, 63-64.

JOHNSON, P. J., FISHKIN, A., \& BOURNE. L. E., JR. Effects of procedural variables upon reversal and interdimensional shift performance: II Psychonomic Science, 1966b, 4. 69-70.

KENDLER, H. H., \& KENDLER, T. S. Vertical and horizontal processes in problem solving. Psychological Review, $1962,69,1-16$.

WOLFF, J. L. Concept-shift and discrimination-reversal learning in humans. Psychological Bulletin, 1967, 68 . $369-408$. 